\section{A) Check for updates}

Cite this: Org. Biomol. Chem., 2020, 18,3679

Received 18th March 2020,

Accepted 23rd April 2020

DOI: $10.1039 / d 0 o b 00575 d$

rsc.li/obc

\title{
Synthesis of unsymmetrical benzils via palladium-catalysed $\alpha$-arylation-oxidation of 2-hydroxyacetophenones with aryl bromides $\uparrow$
}

\author{
Takanori Matsuda (iD * and Souta Oyama
}

A diverse set of unsymmetrically substituted benzils were facilely synthesised by a cross-coupling reaction between 2-hydroxyacetophenones and aryl bromides in the presence of a palladium catalyst. Experimental studies suggested a reaction mechanism involving a one-pot tandem palladium-catalysed $\alpha$-arylation and oxidation, where aryl bromides play a dual role as mild oxidants as well as arylating agents.

\section{Introduction}

1,2-Diketones are members of an important class of molecules with diverse application potential in various fields. They are useful building blocks for the synthesis of a range of carboand heterocyclic compounds, ${ }^{1}$ and 1,2-diketone-derived compounds have been utilised as ligands for transition metals. ${ }^{2}$ Among these 1,2-diketones, benzils (diphenylethanediones) are recognised as privileged scaffolds that have distinct properties, and they can be converted into compounds with vicinal diphenyl groups. Benzils are generally synthesised via oxidation of the corresponding benzoins, ${ }^{3}$ diarylacetylenes, ${ }^{4}$ or other 1,2-diphenyl derivatives. ${ }^{5}$ Thus, the traditional synthesis of unsymmetrical benzils necessitates the preparation of unsymmetrical starting materials, which can complicate the process considerably. In this context, significant advances have recently been made, whereby coupling strategies offer a viable and effective procedure for the synthesis of unsymmetrical benzils. ${ }^{6,7}$ In particular, a reaction employing an aryl halide as the aryl source would be advantageous, as a large number of aryl halides are currently commercially available and relatively inexpensive.

Palladium-catalysed $\alpha$-arylation of ketones with aryl halides, enabling cross-coupling between an electrophilic aryl group and a nucleophilic ketone enolate, represents a versatile and robust method for the synthesis of $\alpha$-aryl ketones. ${ }^{8}$ Although the $\alpha$-arylation of other carbonyl compounds, such as esters and aldehydes, as well as nitriles, and nitroalkanes has been well established, ${ }^{9}$ to date, there have been no reports on a reac-

Department of Applied Chemistry, Tokyo University of Science, 1-3 Kagurazaka, Shinjuku-ku, Tokyo 162-8601, Japan. E-mail: mtd@rs.tus.ac.jp

$\dagger$ Electronic supplementary information (ESI) available: Experimental procedures and characterisation data for new compounds. See DOI: 10.1039/d0ob00575d tion utilizing $\alpha$-hydroxy ketones as nucleophiles. In this paper, we report that palladium(0)-catalysed $\alpha$-arylation of 2-hydroxyacetophenones with aryl bromides produces benzoins, which are subsequently oxidised to benzils through the action of aryl bromides as mild oxidants, under catalytic conditions. In reactions of $\alpha$-hydroxy ketones with two nucleophilic sites, $C$-arylation is particularly favoured over $O$-arylation. ${ }^{10}$ Moreover, a control experiment revealed that 2-hydroxyacetophenones are more prone to $\alpha$-arylation than acetophenone.

\section{Results and discussion}

2-Hydroxyacetophenone (1a) and 4-bromotoluene (2a, 2 equiv.) were heated in toluene at $100{ }^{\circ} \mathrm{C}$ in the presence of $10 \mathrm{~mol} \%$ $\mathrm{Pd}\left(\mathrm{PPh}_{3}\right)_{4}$ as the catalyst and $\mathrm{NaO} t$ - $\mathrm{Bu}$ as a base for $24 \mathrm{~h}$ (Table 1 , entry 1 ). The reaction primarily resulted in a reductive homocoupling to afford a biaryl, and no cross-coupling was observed. In contrast, when $[\mathrm{PdCl}(\text { allyl })]_{2}$ was employed as the catalyst, cross-coupling between 1a and 2a occurred, but the benzil product 3aa was isolated in only $9 \%$ yield (entry 2 ). The anticipated $\alpha$-arylation product, benzoin, was not detected in the reaction mixture, indicating that oxidation had occurred concomitantly during the reaction. To increase the product yield, we examined various phosphine ligands and found that XPhos ${ }^{11}$ was the most effective (36\% yield) among those examined (entries 3-8). As for the palladium complexes, [PdCl (allyl) $]_{2}$ was found to be the complex of choice for this reaction (entries 8-11).

As the decomposition of benzil 3aa was observed with longer reaction times under the conditions employing $\mathrm{NaO} t$ $\mathrm{Bu}$, further optimisation was performed (Table 2). An extensive investigation into the choice of base (entries 1-6) indicated that the use of $\mathrm{K}_{3} \mathrm{PO}_{4}$ resulted in a cleaner reaction, furnishing 3aa in $62 \%$ yield within $6 \mathrm{~h} ;{ }^{12}$ the yield was further improved 
Table 1 Screening of palladium complexes and phosphine ligands for the palladium-catalysed coupling of 2-hydroxyacetophenone (1a) with 4-bromotoluene $(2 a)^{a}$

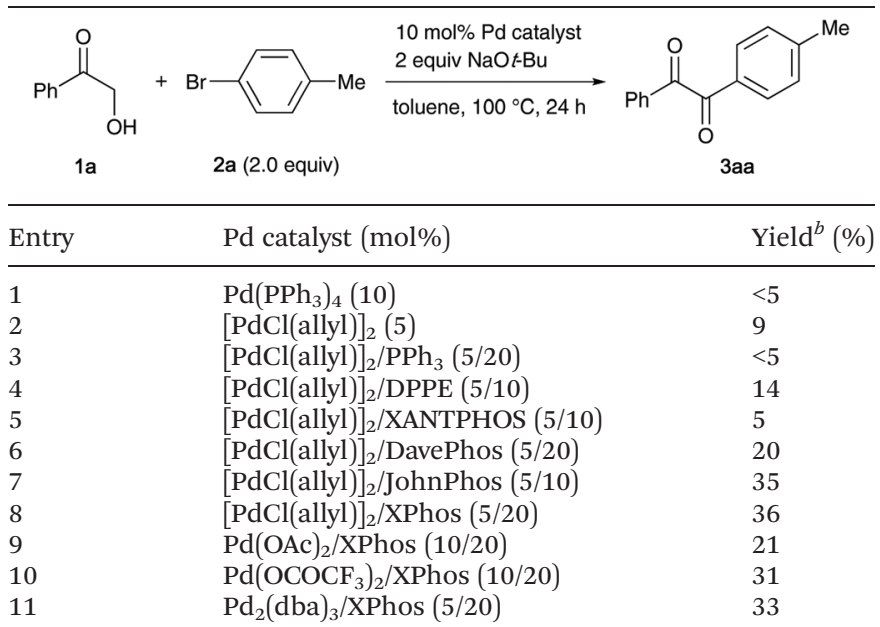

${ }^{a}$ Reaction conditions: 1a $(0.100 \mathrm{mmol}), 2 \mathrm{a}(0.200 \mathrm{mmol})$, Pd complex (10 mol\%), phosphine ligand $(20 / 10 \mathrm{~mol} \%$ for monodentate/bidentate), $\mathrm{NaO} t-\mathrm{Bu}(0.200 \mathrm{mmol})$, and toluene $(0.5 \mathrm{~mL})$ at $100{ }^{\circ} \mathrm{C}$ for $24 \mathrm{~h}$. ${ }^{b}$ Isolated yield.

Table 2 Screening of bases and solvents ${ }^{a}$

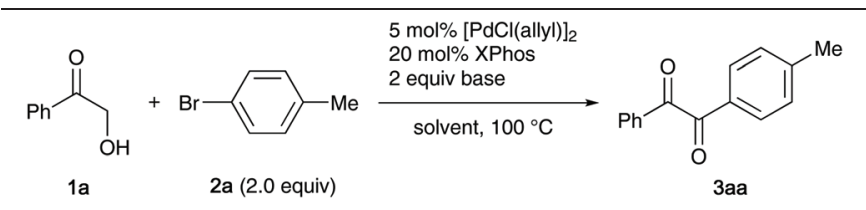

\begin{tabular}{|c|c|c|c|c|}
\hline Entry & Base & Solvent & Time (h) & Yield $^{b}(\%)$ \\
\hline 1 & $\mathrm{NaO} t-\mathrm{Bu}$ & Toluene & 6 & 56 \\
\hline 2 & $\mathrm{KO} t-\mathrm{Bu}$ & Toluene & 6 & 22 \\
\hline 3 & $\mathrm{NaN}\left(\mathrm{SiMe}_{3}\right)_{2}$ & Toluene & 6 & 32 \\
\hline 4 & $\mathrm{Cs}_{2} \mathrm{CO}_{3}$ & Toluene & 6 & 33 \\
\hline 5 & $\mathrm{~K}_{2} \mathrm{CO}_{3}$ & Toluene & 6 & 35 \\
\hline 6 & $\mathrm{~K}_{3} \mathrm{PO}_{4}$ & Toluene & 6 & 62 \\
\hline 7 & $\mathrm{~K}_{3} \mathrm{PO}_{4}$ & Toluene & 18 & 80 \\
\hline 8 & $\mathrm{~K}_{3} \mathrm{PO}_{4}$ & 1,4-Dioxane & 18 & 72 \\
\hline 9 & $\mathrm{~K}_{3} \mathrm{PO}_{4}$ & THF & 18 & 70 \\
\hline 10 & $\mathrm{~K}_{3} \mathrm{PO}_{4}$ & $\mathrm{ClCH}_{2} \mathrm{CH}_{2} \mathrm{Cl}$ & 18 & 33 \\
\hline 11 & $\mathrm{~K}_{3} \mathrm{PO}_{4}$ & DMF & 18 & 25 \\
\hline 12 & $\mathrm{~K}_{3} \mathrm{PO}_{4}$ & EtOH & 18 & 33 \\
\hline 13 & $\mathrm{~K}_{3} \mathrm{PO}_{4}$ & $t$-BuOH & 18 & 80 \\
\hline $14^{c}$ & $\mathrm{~K}_{3} \mathrm{PO}_{4}$ & $t$-BuOH & 18 & 90 \\
\hline $15^{c, d}$ & $\mathrm{~K}_{3} \mathrm{PO}_{4}$ & $t-\mathrm{BuOH}$ & 18 & 83 \\
\hline $16^{c, e}$ & $\mathrm{~K}_{3} \mathrm{PO}_{4}$ & $t-\mathrm{BuOH}$ & 18 & 25 \\
\hline $17^{c, f}$ & $\mathrm{~K}_{3} \mathrm{PO}_{4}$ & $t-\mathrm{BuOH}$ & 18 & 91 \\
\hline
\end{tabular}

${ }^{a}$ Reaction conditions: 1a (0.100 mmol), 2a (0.200 mmol), [PdCl(allyl) $]_{2}$ (0.005 mmol, $10 \mathrm{~mol} \% \mathrm{Pd}$ ), XPhos (0.020 mmol, $20 \mathrm{~mol} \%$ ), base $(0.200 \mathrm{mmol})$ and solvent $(0.5 \mathrm{~mL})$ at $100{ }^{\circ} \mathrm{C}$ for the indicated time unless otherwise noted. ${ }^{b}$ Isolated yield. ${ }^{c} 2.5$ equiv. $(0.250 \mathrm{mmol})$ each of $2 \mathrm{a}$ and $\mathrm{K}_{3} \mathrm{PO}_{4}$ were used. ${ }^{d} 2.5 \mathrm{~mol} \%[\mathrm{PdCl}(\text { allyl })]_{2}(5.0 \mathrm{~mol} \% \mathrm{Pd})$ was used. ${ }^{e} 1.0 \mathrm{~mol} \%[\mathrm{PdCl}(\mathrm{allyl})]_{2}(2.0 \mathrm{~mol} \% \mathrm{Pd})$ was used. ${ }^{f} \mathbf{1 a}$ $(6.00 \mathrm{mmol})$ was reacted under reflux.

to $80 \%$ when the reaction time was $18 \mathrm{~h}$ (entry 7 ). Notably, the reaction proceeded smoothly without the need for stronger bases, such as alkoxides. Solvent screening confirmed that

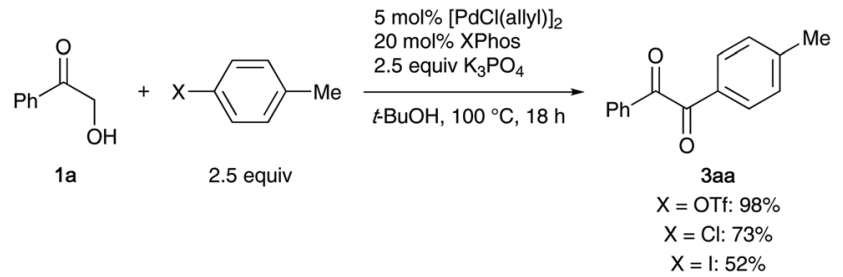

Scheme 1 Comparison of the reactivity of aryl halides and triflate.

$t$ - $\mathrm{BuOH}$ was the optimal solvent, giving superior results in terms of the prevention of decomposition of $\alpha$-hydroxy ketone 1a (entries 7-13). Finally, the use of 2.5 equiv. of both the aryl bromide $2 \mathrm{a}$ and the base afforded 3aa in $90 \%$ yield (entry 14 ). The reaction with $5 \mathrm{~mol} \%$ catalyst loading provided a comparable yield, while the yield deteriorated with further catalyst loading reduction to $2 \mathrm{~mol} \%$ (entries 15 and 16). The coupling was successfully performed on a gram scale to furnish $1.2 \mathrm{~g}$ of 3 aa in $91 \%$ yield (entry 17 ).

The reaction proved efficient using an aryl triflate, providing 3aa in 98\% yield (Scheme 1). A slight decrease in yield was observed for aryl chlorides. In the case of an aryl iodide, however, the yield was reduced to $52 \%$ due to the competing biaryl homocoupling.

With the optimised conditions in hand, we investigated the scope of the coupling reaction and found that a diverse array of unsymmetrical benzils, as well as the parent benzil could be effectively synthesised (Table 3). Coupling of 1a with bromobenzenes $2 \mathbf{c}-\mathbf{g}$ bearing electron-donating and electron-withdrawing substituents at the meta- or para-positions afforded the corresponding benzils 3ac-ag in 61-98\% yields (entries 2-6). Moreover, it was established that the reaction was effective in the presence of heteroatom substituents (entries 7-10). The reaction using 2- and 1-naphthyl bromides $2 \mathbf{l}$ and $2 \mathbf{m}$ delivered 1,2-diketones $\mathbf{3 a l}$ and $\mathbf{3 a m}$ in $79 \%$ and $58 \%$ yields, respectively, (entries 11 and 12). However, the yields of 3 declined considerably when ortho-substituted bromobenzenes $2 \mathrm{n}$ and 20 were used (entries 13 and 14). The attempted reaction with 4-bromophenol afforded only a trace amount of the desired product, and the formation of complex product mixtures was observed with 1-bromo-3-nitrobenzene and 3'bromoacetophenone. ${ }^{13}$ Furthermore, a variety of $\alpha$-hydroxy ketones $\mathbf{1 b} \mathbf{b} \mathbf{k}$, including naphthyl and heteroaryl ketones, also underwent the coupling reaction with $\mathbf{2 a}$ to deliver $3 \mathbf{b a - k a}$ (entries 15-24). ${ }^{14}$ Finally, it was demonstrated that additional unsymmetrical benzils, including highly electronically biased 3ee, could be obtained by the coupling protocol (entries 25-31).

Several control experiments were conducted to elucidate the mechanistic aspects of the coupling reaction (Scheme 2). When the reaction was terminated after $1 \mathrm{~h}$, benzoin 4aa was isolated in $49 \%$ yield in addition to benzil 3aa (37\%), suggesting that $4 \mathbf{a a}$ is the initial product, and that 3aa is subsequently formed by the oxidation of 4aa (Scheme 2A). The preference of $\alpha$-arylation of $\alpha$-hydroxy ketone 1a over acetophe- 
Table 3 Scope of palladium-catalysed $\alpha$-arylation-oxidation of 1 with $2^{a}$

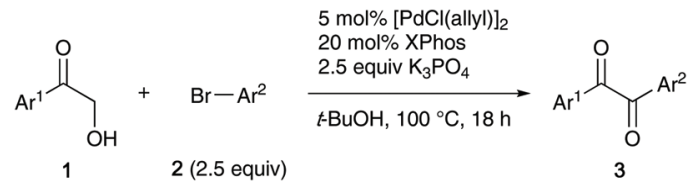

\begin{tabular}{|c|c|c|c|c|}
\hline Entry & $1\left(\mathrm{Ar}^{1}\right)$ & $2\left(\mathrm{Ar}^{2}\right)$ & 3 & Yield $^{b}[\%]$ \\
\hline 1 & $1 \mathbf{a}(\mathrm{Ph})$ & $2 \mathbf{b}(\mathrm{Ph})$ & $3 a b$ & 88 \\
\hline 2 & $1 \mathbf{a}(\mathrm{Ph})$ & $2 \mathrm{c}\left(4-t-\mathrm{BuC}_{6} \mathrm{H}_{4}\right)$ & $3 a c$ & 86 \\
\hline 3 & $\mathbf{1 a}(\mathrm{Ph})$ & $2 d\left(3-\mathrm{MeC}_{6} \mathrm{H}_{4}\right)$ & 3ad & 98 \\
\hline 4 & $1 \mathbf{a}(\mathrm{Ph})$ & $2 \mathrm{e}\left(4-\mathrm{MeOC}_{6} \mathrm{H}_{4}\right)$ & 3ae & 78 \\
\hline 5 & 1a $(\mathrm{Ph})$ & $2 \mathbf{f}\left(4-\mathrm{F}_{3} \mathrm{CC}_{6} \mathrm{H}_{4}\right)$ & 3 af & 70 \\
\hline 6 & $1 \mathbf{a}(\mathrm{Ph})$ & $2 \mathrm{~g}\left(3-\mathrm{MeO}_{2} \mathrm{CC}_{6} \mathrm{H}_{4}\right)$ & $3 a g$ & 61 \\
\hline 7 & $1 \mathbf{a}(\mathrm{Ph})$ & $2 \mathbf{h}\left(4-\mathrm{FC}_{6} \mathrm{H}_{4}\right)$ & 3ah & 89 \\
\hline 8 & $1 \mathbf{a}(\mathrm{Ph})$ & $2 \mathrm{i}\left(4-\mathrm{Me}_{3} \mathrm{SiC}_{6} \mathrm{H}_{4}\right)$ & 3ai & 98 \\
\hline 9 & $1 \mathbf{a}(\mathrm{Ph})$ & $2 \mathrm{j}\left(3-\mathrm{MeSC}_{6} \mathrm{H}_{4}\right)$ & 3aj & 76 \\
\hline 10 & $1 \mathbf{a}(\mathrm{Ph})$ & $2 \mathbf{k}\left(3-(\text { dan }) \mathrm{BC}_{6} \mathrm{H}_{4}\right)^{c}$ & 3ak & 49 \\
\hline 11 & $\mathbf{1 a}(\mathrm{Ph})$ & $2 \mathbf{l}$ (2-naphthyl) & 3al & 79 \\
\hline 12 & $1 \mathbf{a}(\mathrm{Ph})$ & 2m (1-naphthyl) & 3am & 58 \\
\hline 13 & $1 \mathbf{a}(\mathrm{Ph})$ & 2 n $\left(2-\mathrm{MeC}_{6} \mathrm{H}_{4}\right)$ & 3an & 45 \\
\hline 14 & $1 \mathbf{a}(\mathrm{Ph})$ & $20\left(2-\mathrm{MeOC}_{6} \mathrm{H}_{4}\right)$ & 3 ao & 44 \\
\hline 15 & $\mathbf{1 b}\left(4-\mathrm{MeC}_{6} \mathrm{H}_{4}\right)$ & $2 \mathbf{a}\left(4-\mathrm{MeC}_{6} \mathrm{H}_{4}\right)$ & $3 \mathbf{b a}$ & 92 \\
\hline 16 & 1c $\left(3-\mathrm{MeC}_{6} \mathrm{H}_{4}\right)$ & $2 \mathbf{a}\left(4-\mathrm{MeC}_{6} \mathrm{H}_{4}\right)$ & $3 c a$ & 95 \\
\hline 17 & 1d $\left(3-\mathrm{MeOC}_{6} \mathrm{H}_{4}\right)$ & $2 \mathbf{a}\left(4-\mathrm{MeC}_{6} \mathrm{H}_{4}\right)$ & 3da & 78 \\
\hline 18 & $1 e\left(4-\mathrm{F}_{3} \mathrm{CC}_{6} \mathrm{H}_{4}\right)$ & $2 \mathbf{a}\left(4-\mathrm{MeC}_{6} \mathrm{H}_{4}\right)$ & 3ea & 64 \\
\hline 19 & 1f $\left(4-\mathrm{FC}_{6} \mathrm{H}_{4}\right)$ & $2 \mathbf{a}\left(4-\mathrm{MeC}_{6} \mathrm{H}_{4}\right)$ & $3 \mathrm{fa}$ & 79 \\
\hline 20 & $\lg \left(2-\mathrm{MeC}_{6} \mathrm{H}_{4}\right)$ & $2 \mathbf{a}\left(4-\mathrm{MeC}_{6} \mathrm{H}_{4}\right)$ & $3 g a$ & 71 \\
\hline 21 & 1h (2-naphthyl) & $2 \mathbf{a}\left(4-\mathrm{MeC}_{6} \mathrm{H}_{4}\right)$ & 3 ha & 74 \\
\hline 22 & 1i (1-naphthyl) & $2 \mathbf{a}\left(4-\mathrm{MeC}_{6} \mathrm{H}_{4}\right)$ & $3 i a$ & 72 \\
\hline 23 & $\mathbf{1 j}$ (2-furyl) & $2 \mathbf{a}\left(4-\mathrm{MeC}_{6} \mathrm{H}_{4}\right)$ & $3 \mathbf{j a}$ & 55 \\
\hline 24 & 1k (2-thienyl) & $2 \mathbf{a}\left(4-\mathrm{MeC}_{6} \mathrm{H}_{4}\right)$ & 3ka & 76 \\
\hline 25 & $1 d\left(3-\mathrm{MeOC}_{6} \mathrm{H}_{4}\right)$ & $2 \mathrm{e}\left(4-\mathrm{MeOC}_{6} \mathrm{H}_{4}\right)$ & 3de & 71 \\
\hline 26 & $1 \mathrm{e}\left(4-\mathrm{F}_{3} \mathrm{CC}_{6} \mathrm{H}_{4}\right)$ & $2 \mathrm{e}\left(4-\mathrm{MeOC}_{6} \mathrm{H}_{4}\right)$ & 3ee & 59 \\
\hline 27 & $1 \mathrm{~g}\left(2-\mathrm{MeC}_{6} \mathrm{H}_{4}\right)$ & $2 \mathbf{f}\left(4-\mathrm{F}_{3} \mathrm{CC}_{6} \mathrm{H}_{4}\right)$ & $3 g f$ & 65 \\
\hline 28 & $1 \mathrm{~g}\left(2-\mathrm{MeC}_{6} \mathrm{H}_{4}\right)$ & 21 (2-naphthyl) & $3 g l$ & 70 \\
\hline 29 & 1h (2-naphthyl) & $2 \mathbf{f}\left(4-\mathrm{F}_{3} \mathrm{CC}_{6} \mathrm{H}_{4}\right)$ & 3 hf & 62 \\
\hline 30 & 1i (1-naphthyl) & $2 \mathbf{f}\left(4-\mathrm{F}_{3} \mathrm{CC}_{6} \mathrm{H}_{4}\right)$ & 3if & 61 \\
\hline 31 & 1k (2-thienyl) & $2 \mathbf{l}$ (2-naphthyl) & $3 \mathbf{k l}$ & 82 \\
\hline
\end{tabular}

${ }^{a}$ Reaction conditions: 1 (0.200 mmol), $2(0.500 \mathrm{mmol}),[\mathrm{PdCl}(\text { allyl })]_{2}$ (0.010 mmol, $10 \mathrm{~mol} \% \mathrm{Pd})$, XPhos $(0.040 \mathrm{mmol}, 20 \mathrm{~mol} \%), \mathrm{K}_{3} \mathrm{PO}_{4}$ $(0.500 \mathrm{mmol})$ and $t$ - $\mathrm{BuOH}(0.5 \mathrm{~mL})$ at $100{ }^{\circ} \mathrm{C}$ for $18 \mathrm{~h} .{ }^{b}$ Isolated yield. ${ }^{c} \mathrm{~B}(\mathrm{dan})=$ naphtho[1,8-de $][1,3,2]$ diazaborinin-2-yl.

none (5) was confirmed by a competition experiment with equimolar amounts of $\mathbf{1 a}$ and $\mathbf{5}$ under the standard conditions. After $1 \mathrm{~h}$, 3aa and 4aa were isolated in 85\% combined yield while 5, lacking the hydroxyl group, remained intact (Scheme 2B). Palladium-catalysed oxidation of alcohols using aryl halides as oxidants has been reported. ${ }^{15}$ Indeed, oxidation of benzoin (4ab) with $2 \mathbf{a}$ in the presence of the Pd-XPhos catalyst and $\mathrm{K}_{3} \mathrm{PO}_{4}$ in $t$-BuOH furnished benzil (3ab) in a high yield, whereas the oxidation of $4 \mathbf{a b}$ failed to occur in the absence of $2 \mathrm{a}$ (Scheme 2C). In the case of the reaction with 1-bromo-4-(tert-butyl)benzene (2c), the formation of tert-butylbenzene $(42 \%)$ was detected by GC along with the quantitative formation of benzil 3ac (Scheme 2D). Another possible scenario involving an initial oxidation of an $\alpha$-hydroxy ketone to a glyoxal, which is subsequently arylated, was excluded, and no arylation of phenylglyoxal (6) was observed under our conditions (Scheme 2E). ${ }^{16}$
(A)

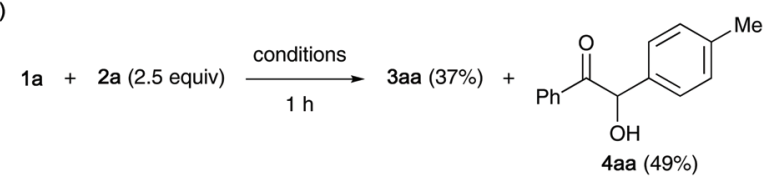

(B)
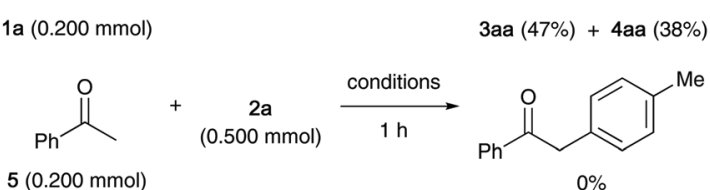

(C)

$5(0.200 \mathrm{mmol})$

$0 \%$

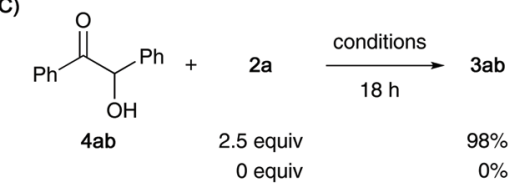

(D)

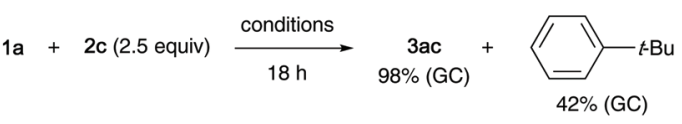

(E)

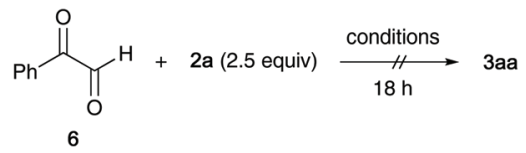

Scheme 2 Control experiments (conditions: $5 \mathrm{~mol} \% \quad[\mathrm{PdCl}(\text { allyl })]_{2}$ 20 mol\% XPhos, 2.5 equiv. $\mathrm{K}_{3} \mathrm{PO}_{4}, t-\mathrm{BuOH}, 100^{\circ} \mathrm{C}$ ).

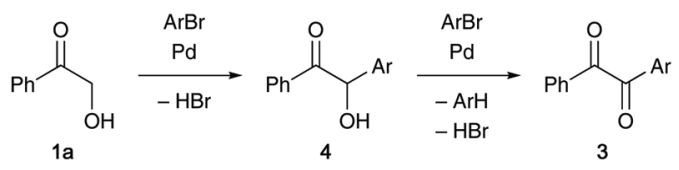

Scheme 3 Mechanism for $\alpha$-arylation-oxidation

Based on these experimental observations, we conclude that the present reaction involves an initial $\alpha$-arylation of 2-hydroxyacetophenone (1a) followed by oxidation of the resulting benzoin 4 to benzil 3 , both of which are catalysed by a palladium complex equipped with XPhos; two equivalents of aryl bromide are consumed during the process (Scheme 3$).{ }^{17}$

\section{Conclusions}

In summary, we have developed a novel synthetic method for accessing unsymmetrical benzils starting from 2-hydroxyacetophenones, achieved by a tandem $\alpha$-arylation-oxidation sequence, both of which are catalysed by a palladium-XPhos system. Readily available aryl bromides initially function as arylating agents to form $\mathrm{C}-\mathrm{C}$ bonds, and then subsequently oxidise the resulting benzoins to benzils, with concomitant hydrodebromination. The widely applicable transformation can be conducted under mild and virtually redox-neutral conditions. $^{18}$ 


\section{Conflicts of interest}

There are no conflicts to declare.

\section{Notes and references}

1 (a) C. Rogers, W. S. Perkins, G. Veber, T. E. Williams, R. R. Cloke and F. R. Fischer, J. Am. Chem. Soc., 2017, 139, 4052-4061; (b) S. Sundar and R. Rengan, Org. Biomol. Chem., 2019, 17, 1402-1409; (c) A. Y. Dubovtsev, D. V. Dar'in, M. Krasavin and V. Y. Kukushkin, Eur. J. Org. Chem., 2019, 1856-1864; (d) Y. Nakagawa, R. Sekiguchi, J. Kawakami and S. Ito, Org. Biomol. Chem., 2019, 17, 68436853; (e) A. Rashidizadeh, H. Ghafuri, H. R. E. Zand and N. Goodarzi, ACS Omega, 2019, 4, 12544-12554; $(f)$ G. Li, Y. Han, Y. Zou, J. J. C. Lee, Y. Ni and J. Wu, Angew. Chem., Int. Ed., 2019, 58, 14319-14326; (g) T. T. Nguyen, N.-P. T. Le, T. T. Nguyen and P. H. Tran, RSC Adv., 2019, 9, 38148-38153.

2 (a) K. Ohta, Y. Inagaki-Oka, H. Hasebe and I. Yamamoto, Polyhedron, 2000, 19, 267-274; (b) J. L. Dempsey, B. S. Brunschwig, J. R. Winkler and H. B. Gray, Acc. Chem. Res., 2009, 42, 1995-2004; (c) F. Wang and C. Chen, Polym. Chem., 2019, 10, 2354-2369.

3 For recent examples, see: (a) P. Muthupandi and G. Sekar, Tetrahedron Lett., 2011, 52, 692-695; (b) Y. Yu, C. Lin, B. Li, P. Zhao and S. Zhang, Green Chem., 2016, 18, 3647-3655; (c) A. Saha, S. Payra and S. Banerjee, New J. Chem., 2017, 41, 13377-13381; (d) A. R. Patel, G. Patel and S. Banerjee, ACS Omega, 2019, 4, 2244522455.

4 For recent examples, see: (a) J.-W. Xue, M. Zeng, X. Hou, Z. Chen and G. Yin, Asian J. Org. Chem., 2018, 7, 212219; (b) S. W. Kim, T.-W. Um and S. Shin, J. Org. Chem., 2018, 83, 4703-4711; (c) J. Zhou, X.-Z. Tao, J.-J. Dai, C.-G. Li, J. Xu, H.-M. Xu and H.-J. Xu, Chem. Commun., 2019, 55, 9208-9211; (d) W. Yang, Y. Chen, Y. Yao, X. Yang, Q. Lin and D. Yang, J. Org. Chem., 2019, 84, 11080-11090; (e) A. Y. Dubovtsev, N. V. Shcherbakov, D. V. Dar'in and V. Y. Kukushkin, J. Org. Chem., 2020, 85, 745-757.

5 For recent examples, see: (a) X. Liu and W. Chen, Organometallics, 2012, 31, 6614-6622; (b) X. Zeng, C. Miao, S. Wang, C. Xia and W. Sun, RSC Adv., 2013, 3, 9666-9669; (c) J.-W. Yu, S. Mao and Y.-Q. Wang, Tetrahedron Lett., 2015, 56, 1575-1580; (d) R. Chebolu, A. Bahuguna, R. Sharma, V. K. Mishra and P. C. Ravikumar, Chem. Commun., 2015, 51, 15438-15441; (e) J. M. Khurana, A. Lumb and A. Chaudhary, Monatsh. Chem., 2017, 148, 381-386.

6 For oxidative coupling reactions, see: (a) Q. Zhang, C.-M. Xu, J.-X. Chen, X.-L. Xu, J.-C. Ding and H.-Y. Wu, Appl. Organomet. Chem., 2009, 23, 524-526; (b) X. Guo, W. Li and Z. Li, Eur. J. Org. Chem., 2010, 5787-5790; (c) M. R. Rohman, I. Kharkongor, M. Rajbangshi,
H. Mecadon, B. M. Laloo, P. R. Sahu, I. Kharbangar and B. Myrboh, Eur. J. Org. Chem., 2012, 320-328; (d) Y. Su, X. Sun, G. Wu and N. Jiao, Angew. Chem., Int. Ed., 2013, 52, 9808-9812; (e) W.-X. Lv, Y.-F. Zeng, S.-S. Zhang, Q. Li and H. Wang, Org. Lett., 2015, 17, 2972-2975; $(f)$ J. B. Bharate, S. Abbat, R. Sharma, P. V. Bharatam, R. A. Vishwakarma and S. B. Bharate, Org. Biomol. Chem., 2015, 13, 5235-5242; (g) P. Hirapara, D. Riemer, N. Hazra, J. Gajera, M. Finger and S. Das, Green Chem., 2017, 19, 5356-5360; (h) Y. Kumar, Y. Jaiswal and A. Kumar, Eur. J. Org. Chem., 2018, 494-505.

7 For one-pot syntheses via Sonogashira/Heck couplingoxidation, see: (a) H. Min, T. Palani, K. Park, J. Hwang and S. Lee, J. Org. Chem., 2014, 79, 6279-6285; (b) D. Saberi, H. Hashemi and K. Niknam, Asian J. Org. Chem., 2017, 6, 169-173; (c) V. G. Jadhav, S. A. Sarode and J. M. Nagarkar, Tetrahedron Lett., 2017, 58, 18341838; (d) P. Niesobski, I. S. Martínez, S. Kustosz and T. J. J. Müller, Eur. J. Org. Chem., 2019, 52145218.

8 (a) M. Palucki and S. L. Buchwald, J. Am. Chem. Soc., 1997, 119, 11108-11109; (b) B. C. Hamann and J. F. Hartwig, J. Am. Chem. Soc., 1997, 119, 12382-12383.

9 (a) W. A. Moradi and S. L. Buchwald, J. Am. Chem. Soc., 2001, 123, 7996-8002; (b) S. Lee, N. A. Beare and J. F. Hartwig, J. Am. Chem. Soc., 2001, 123, 8410-8411; (c) E. M. Vogl and S. L. Buchwald, J. Org. Chem., 2002, 67, 106-111; (d) D. A. Culkin and J. F. Hartwig, J. Am. Chem. Soc., 2002, 124, 9330-9331; (e) R. Martín and S. L. Buchwald, Angew. Chem., Int. Ed., 2007, 46, 7236-7239; (f) G. D. Vo and J. F. Hartwig, Angew. Chem., Int. Ed., 2008, 47, 2127-2130. For a review on $\alpha$-arylation, see: (g) C. C. C. Johansson and T. J. Colacot, Angew. Chem., Int. Ed., 2010, 49, 676-707.

10 (a) M. Palucki, J. P. Wolfe and S. L. Buchwald, J. Am. Chem. Soc., 1997, 119, 3395-3396; (b) K. E. Torraca, X. Huang, C. A. Parrish and S. L. Buchwald, J. Am. Chem. Soc., 2001, 123, 10770-10771; (c) H. Zhang, P. Ruiz-Castillo and S. L. Buchwald, Org. Lett., 2018, 20, 1580-1583.

11 2-Dicyclohexylphosphino-2',4',6'-triisopropylbiphenyl.

12 The use of organic bases, such as $\mathrm{Et}_{3} \mathrm{~N}$ and $\mathrm{DBU}$ resulted in virtually no reaction.

13 The reaction of $1 \mathrm{a}$ with 2-bromopyridine led to decomposition of the starting materials.

14 The attempted coupling of ethyl hydroxyacetate with 2a failed, producing a complex mixture of products. Hydroxyacetone was not suitable for the reaction.

15 (a) A. S. Guram, X. Bei and H. W. Turner, Org. Lett., 2003, 5, 2485-2487; (b) C. Berini, D. F. Brayton, C. Mocka and O. Navarro, Org. Lett., 2009, 11, 4244-4247; (c) Q. Gao and S. Xu, Org. Biomol. Chem., 2018, 16, 208-212; (d) M. Kuriyama, S. Nakashima, T. Miyagi, K. Sato, K. Yamamoto and O. Onomura, Org. Chem. Front., 2018, 5, 2364-2369. 
16 Syntheses of benzophenones by the palladium-catalysed coupling of benzaldehydes with aryl halides have been reported. (a) B. Suchand and G. Satyanarayana, J. Org. Chem., 2016, 81, 6409-6423; (b) T. Wakai, T. Togo, D. Yoshidome, Y. Kuninobu and M. Kanai, ACS Catal., 2018, 8, 3123-3128.
17 The reaction with 1.2 equiv. 2a under air afforded 3a in $45 \%$ yield, indicating that aerobic oxidation was impractical under our conditions. See ref. 6 a.

18 For an account on the synthesis 1,2-diketones from $\alpha$-hydroxy ketones, see: H. Liang, H. Liu and X. Jiang, Synlett, 2016, 2774-2782. 